\section{Representações da violência em ato: ๑ exemplo de dois grupos de trabalhadores sociais}

\section{RESUMO}

Baseado numa pesquisa de campo, este breve artigo trata das representações da violência em dois grupos de trabalhadores sociais na França, em situação de interação com usuários beneficiados pelos serviços de ajuda social.

\section{ABSTRACT}

Based on a research among groups of social workers in France, this article deals with representations of violence in two of them. These workers are interacting with other users of services of social aid.

\section{PALAVRAS-CHAVE (KEY WORDS)}

- Violência (violence)

- Representações (representations)

- Trabalho social (social work)

\section{Emmanuel Gleyze*}

IRSA-CRI/Montpellier III
A etnóloga Françoise Héritier explica que a violência e a intolerância emergem em certas condições particulares, a partir de um conjunto complexo de matrizes antropológicas fundamentais (diferença sexual visível, regularidades cosmológicas, necessidades biológicas e suas conseqüências...). Segundo ela, "a violência intervém nos interstícios sem regras do jogo entrecruzado dessas diversas (e precisas) necessidades" ${ }^{\prime 1}$. Pretende-se, então, nessas páginas, apreender uma das numerosas variações, no sentido quase musical, da violência sob o ângulo das suas representações ${ }^{2}$.

O princípio metodológico da nossa pesquisa é simples. Trata-se de evitar todo circuito oficial e hierárquico, com a intenção de apreender as representações sociais ${ }^{3}$ de dois grupos de trabalhadores sociais. $\mathrm{O}$ primeiro atuando na região parisiense (seis pessoas, das quais cinco são mulheres) ${ }^{4}$, o segundo exercendo suas atividades no sul da França, no departamento do Herault (seis mulheres). No total, foram realizadas 12 entrevistas sem que os temas fossem anunciados antes dos encontros, fazendo funcionar as redes ${ }^{5}$, tendo como objetivo permitir uma construção a mais espontânea possível do que é "a violência" para os entrevistados. Queremos interrogar as categorias do pensamento, porém através de uma ordem bem precisa, por dedução. Trata-se então de "forçar" a pessoa entrevistada a teorizar, definir e conceitualizar desde o início (começando o encontro por um teste de associações de idéias ${ }^{6}$ sobre o tema). Em seguida, questioná-la sobre casos concretos, vividos, em que ela poderia dizer : 
"estou diante de uma situação de violência". Em suma, passar dos fatos falados aos fatos experienciados. Enfim, nesta mesma lógica, trata-se de interrogar e analisar os discursos sobre as estratégias de comunicação (de reação ou de prevenção) utilizadas pelo trabalhador social nestas situações, em interação com outros atores.

Como objeto de análise, limitamo-nos então a uma única profissão, já antiga e solidamente estabelecida na paisagem do trabalho social na França ${ }^{7}$, aquela dos assistentes sociais, a fim de evitar a confusão do labirinto que delimita as profissões que podem ou não se definir como fazendo parte da nebulosa dos trabalhadores sociais ${ }^{8}$.

A questão inicial que motivou este trabalho é bastante simples: como esses dois grupos de assistentes sociais definem a violência e qual tipo de discurso eles elaboram no que diz respeito as suas ações (fatos experimentados em torno da violência)?

\section{Das violências e dos atores, da abstração à experimentação}

Se a relação de desdobramento entre características físicas e aspectos "verbais" é associada à palavra violência no teste de associação de idéias em algumas entrevistas (três para o primeiro grupo e dois para o segundo), em compensação, sete entrevistas, do total de 12, evocam espontaneamente a noção de violência institucional. Além de constar no simples teste de associação, o tema, onipresente, atravessa todas as entrevistas e declina-se, ao nosso ver, de três maneiras, tanto no nível da definição da própria violência quanto nos relatos de experiências:

a) Violências institucionais dos trabalhadores sociais contra os "usuários" (evocadas em três entrevistas), por exemplo: "é a pressão permanente que faz com que o trabalho não seja feito corretamente, sob o pretexto de precisar fazê-lo rapidamente, e que a qualidade seja negligenciada em re- lação à quantidade", tendo conseqüências sobre a qualidade das trocas, da escuta, dos conselhos, da ajuda.

b) Violências e pressões das instituições em geral (Serviços sociais, Abono Familiar, Administração Municipal, etc.) contra esses mesmos "usuários": reclamação de mau atendimento, por exemplo, ou do fato de fazer as pessoas "passearem" de serviço em serviço, ou ainda a perda de documentos importantes, etc.

c) Enfim, violências das instituições (empregador: prefeitura, Conselho Geral, hierarquia interna, etc.) em relação aos trabalhadores sociais (em cinco, das 12 entrevistas), traduzem por vezes um certo "autoritarismo" dos políticos, ou a falta de meios concedidos aos trabalhadores sociais ou, ainda, neste caso explicado por uma assistente social: "quando um superior te diz para deixares tudo, parares o que estás fazendo, e que é importante para ti e para as pessoas que tu atendes, ou te diz para fazeres outra coisa porque a pessoa encarregada por aquela função está ausente; para mim, isso é uma violência, é não me dar importância, não me respeitar no meu trabalho e no que eu sou, (...) é, por conseqüência, não respeitar a pessoa que eu atendo". Daí um sentimento de impotência, freqüentemente evocado entre os trabalhadores sociais.

A temática das violências físicas (geralmente menos aparentes nas suas formas) percorre dez entrevistas. Por exemplo, a queixa das cuspidas sobre os trabalhadores sociais. Outros exemplos extremos: um "usuário" que ameaça um centro social com um isqueiro e um botijão de gás, ou outro que ameaça uma assistente social com um canivete para obter uma consulta, etc. Normalmente, essas ameaças dificilmente passam ao ato.

Enfim as violências verbais são abordadas em três entrevistas (em duas sob a forma do teste de associação de idéias). 


\section{Os três tipos de estratégia: ges- tão em siłuação, prevenção e reparação}

Quando colocamos a seguinte questão: "concretamente, o que você fez (ou faria) diante de uma situação de violência (física, verbal...) no seu ambiente de trabalho?", três tipos de respostas apareceram:

a) $\mathrm{O}$ primeiro diz respeito à gestão do acontecimento: o controle da voz e da atitude, a tentativa de domínio dos movimentos (ir em direção à porta de saída ou marcar uma nova consulta, por exemplo), a conversa, o fato de dedicar-se atenção e falar com a pessoa, entre outros, aparecem como meios possíveis para dominar uma situação potencialmente violenta. Às vezes o próprio fato de continuar sentado e falar sem alterar a voz. Um outro tipo de reação consiste em chamar a atenção dos colegas, (geralmente atentos a acontecimentos desse tipo), o que provoca, em caso de perigo, um agrupamento de pessoas com o objetivo de quebrar a lógica da violência. Se o primeiro Centro Social tem um código que permite chamar por socorro discretamente ("tenho que escrever uma carta para" ou "minha carta está pronta" para dizer diretamente a um colega ou, pelo telefone, à secretaria, para que seja feito um chamado ao posto de polícia), o segundo Centro Social tem, na secretaria, um alarme diretamente ligado ao Conselho Geral que, por sua vez, deve alertar as autoridades competentes. Observa-se aqui um sistema de interações e de solidariedade direta.

b) Um outro conjunto de medidas de comunicação exige interações indiretas, visto que ele trata da prevenção do acontecimento. Por exemplo, o fato de os assistentes sociais entrarem em acordo sobre um código, ou, de a disposição das mesas possibilitar uma saída (rápida e segura) do funcionário, como acontece no Centro Social situado no departamento do Herault. O fato também de que, para certos serviços noturnos, são chamados vigilantes.

c) Por último, existe um conjunto de medidas que visa organizar as ações depois do fato, para permitir a continuidade do bom desenvolvimento dos serviços sociais: pedido de desculpas ao "usuário" que teria "ultrapassado os limites", exclusão temporária e impossibilidade para ele de voltar ao Centro Social durante um período determinado, mudança de funcionário diante de uma situação delicada, processos jurídicos com a cobertura da instituição, encontro com um representante da lei para "enquadrar" a pessoa, ou ainda fechamento momentâneo do Centro com justificativas deste ato, etc. Estamos mais uma vez diante de uma posição de interações indiretas, pós-fato.

Estes três conjuntos de medidas visam, em sua maior parte, garantir a coesão do grupo de trabalhadores sociais (sua proteção por exemplo), mas também assegurar, de uma maneira ou de outra, a continuidade dos elos com os "usuários".

Como conclusão deste breve artigo, podemos prudentemente sugerir ${ }^{9}$ o fato de que o conjunto representacional destes 12 assistentes sociais, acerca da noção de violência, constitui-se em torno de três conjuntos: a violência institucional, a violência física e a violência verbal (sobretudo com a presença dos dois primeiros). Além disso, a existência de uma relação de interação, numa situação de violência ( principalmente física e verbal neste quadro) do "usuário" em relação ao assistente social, acarreta um conjunto de precauções, de auto-controle, de estratégias de comunicação e de reparação que parecem permitir uma boa coesão do grupo dos trabalhadores sociais, bem como uma continuidade correta dos elos com a maioria dos sujeitos $^{10}$ violentos, para situarnos na perspectiva subjetiva da violência defendida por Michel Wieviorka •

\section{Notas}

Texto traduzido do francês por Clélia Pinto 
* Professor substituto e Doutorando em Sociologia na Universidade Paul Valéry - Montpellier III. Pesquisador no Institut de Recherches Sociologiques \& Anthropologiques e no Centre de Recherches sur l'Imaginaire (IRSA-CRI). Contato: gleyze.emmanuel@voilà.fr

1 HÉRITIER, Françoise. Les matrices de l'intolérance et de la violence. In: De la violence. Paris: Odile Jacob, 2005 (1999), Volume II, p. 328.

2 Basta relembrar a noção de noosphère própria à Edgar Morin para apreender toda a importância do estudo das representações como objeto de pesquisa e como um mundo em si: La Méthode. 4. Les idées. Leur habitat, leur vie, leur mours, leur organisation. Paris: Le Seuil, 1991, pp. 105-157.

3 Para uma evocação das representações sociais, ver artigo de Birgitta Orfali, Les représentations sociales: un concept essentiel et une théorie fondamentale en sciences humaines et sociales". In: L'Année sociologique. 2000, 50, n 1 , pp. 235 à 254 ou ainda 0 canônico livro organizado por Denise Jodelet, Les représentations sociales, Paris: PUF, coll. Sociologie d'Aujourd'hui, 1997, notamment pp. 42-78.

4 Na França, 38 mil pessoas exercem atualmente essa profissão (pour les seuls assistants sociaux), com uma percentagem em torno de $93 \%$ de mulheres.

5 Tendo como objetivo, através uma rede, organizar as entrevistas que utilizam ao máximo o que Pierre Bourdieu chama de uma "comunicação não-violenta", e assim reduzir ao maximo a violência simbólica que se estabelece entre 0 entrevistado e o entrevistador, pelo melhoramento do recolhimento dos dados. Ver BOURDIEU, Pierre (coord.). La misère du monde. Paris: Editions du Seuil, coll. Libre Examen, 1993, chapitre Comprendre, pp. 906-907.

60 teste de associações de idéias tem por objetivo permitir ao interlocutor criar associações livres, a partir de uma palavra ou de uma expressão: "Se eu digo a palavra 'violência', você poderia me dar três palavras ou expressões que vêm ao seu espírito espontâneamente?". Ver A. DE ROSA, S. Le réseau d'associations libres comme méthode d'étude dans les recherches sur les représentations sociales. In: Cahiers internationaux de psychologie sociale, 1995, n²8, pp. 96-122.

7 Ver o livro de Emmanuel Jovelin et Brigitte Bouquet,
Histoire des métiers du social en France, Paris, Editions ASH, 2005, em particular o capítulo I: Histoire des assistants de service social, pp. 23-51.

8 Sobre 0 assunto, ver a coletânea de Jacques Ion et Bertrand Ravon, Les travailleurs sociaux, Paris, La Découverte, coll. Repères, 2000, pp. 3-7 (Introduction).

9 É preciso evidententemente completar este breve estudo por uma observação direta de vários meses e por um maior número de entrevistas com trabalhadores e usuários de diversos serviços sociais.

10 WIEVIORKA, Michel. La Violence. Paris: Hachette Littératures, coll. Pluriel/Sociologie, 2005, pp. 283-310, Chapitre 12, La marque du sujet. 